\title{
Optimization of Slug and Concentration for Polymer Surfactant
}

\author{
Yanfu Pi \\ of education of china Petroleum Engineering, Northeast \\ Petroleum University \\ Daqing, China \\ Email: piyanfu@163.com \\ Ya Gong \\ Petroleum Engineering \\ Northeast Petroleum University \\ Daqing, China \\ Email: 455610094@qq.com
}

Key laboratory of enhanced oil and gas recovery of ministry

\author{
Quanzhi Li \\ Petroleum Engineering \\ Northeast Petroleum University, Daqing, China \\ Email:1018798196@qq.com
}

Xiaofang Yang

Technical Service Center of Oil production

Petroleum Engineering Institute of Dagang Oilfield

Tianjin, China

Email:yeyxf@163.com

\begin{abstract}
By comparing the oil displacement experiment of Huading I and Haibo BI polymer surfactant based on the actual the situation of reservoir in Daqing oil field in this paper, the displacement efficiency for two kinds of polymer surfactant in different concentration and different slug were compared. In the optimized concentration experiments, there was an inflection point of increasing range for the degree of reserve recovery when concentration of Huading I and Haibo BI polymer surfactant is $1000 \mathrm{mg} / \mathrm{l}$. The increasing of recovery efficiency slow down gradually with the increasing of concentration; In the optimized slug experiments, the increasing range of the oil recovery was the largest when the injection of Huading $I$ and Haibo BI polymer surfactant was 1 multiple of pore volume injected. Considering concentration and degree of reserve recovery, optimized concentration of Huading I and Haibo BI was $1000 \mathrm{mg} / \mathrm{l}$ and their optimized slug were 1 multiple of pore
\end{abstract} volume injected.

\begin{tabular}{lcr}
\multicolumn{1}{c}{ Keywords-polymer } & surfactant; & slug \\
optimization;concentration & optimization; & oil \\
recovery;polymer flooding & &
\end{tabular}

\section{INTRODUCTION}

Polymer flooding could enhance oil recovery by increasing the viscosity of aqueous phase and decreasing the permeability of aqueous phase to improve mobility ratio and enhance sweep efficiency, which is adding a bit water soluble polymers with high molecular weight[1-2]. Many researchers at home and abroad have always made efforts to the study of oil displacement mechanism for polymer flooding, there has many experiments and researches show that the efficiency of enlarging sweep efficiency and enhancing displacement efficiency are respectively $50 \%$. The field test area of combination flooding has already been carried out in Daqing oilfield, the results show that the increasing of oil recovery is higher by $6 \%-8 \%$ than predicated value which is identified as the function of viscidity and elasticity from elasticoviscous chemical agents which can not only enhance sweep efficiency but only enhance displacement efficiency. The polymer surfactant combines the advantages between polymer and surfactant, incorporates the advantages of tackifying, reducing mobility ratio, enlarging sweep efficiency, improving the ability of solubilizing and emulsifying to crude oil, is a new kind of chemical displacing agent with the single component of a variety of functional groups [3]. Therefore, this part of laboratory experiment has optimized the type of polymer surfactant from Huading I and Haibo BI polymer surfactant, the best concentration of injecting and the size of injection plug [4-6].

\section{THE OPTIMIZATION OF CONCENTRATION} FOR THE TWO KINDS OF POLYMER SURFACTANT

\section{A. Experiment Conditions and Scemes}

The onshore oilfield in this paper is mainly aim at the first kind of reservoir, so the cores in the experiment of optimization of concentration and flug are homogeneous cores whose permeability is $1000 \times 10^{-3} \mu \mathrm{m}^{2}$ and size is $45 \mathrm{~mm} \times 45 \mathrm{~mm} \times 300 \mathrm{~mm}$; the saturated water in the experiment is simulated formation water in Daqing whose degree of mineralization is $6778 \mathrm{mg} / \mathrm{l}$; the experimental oil is simulated oil from No.1 oil Oil Production Plant in Daqing oilfield whose viscosity is $9.8 \mathrm{mPa} \cdot \mathrm{s}$ when the temperature is $45^{\circ} \mathrm{C}$; the experimental polymer is Huading I and Haibo BI polymer surfactant solution in the different concentration; all the experiments are conducted when the temperature is $45^{\circ} \mathrm{C}$; the flooding rate is $0.3 \mathrm{~mL} / \mathrm{min}$. This paper has conducted four displacement experiments, compared the displacement efficiency of the two kinds of polymer surfactant under the different concentration, summarized and analyzed the relationship between the concentration and oil recovery, ensured the best concentration of injecting. The experiment scheme is water flooding to the water cut is $98 \%$ and then polymer flooding whose injection is 0.6 multiples of pore volume injected and concentration is $1000 \mathrm{mg} / \mathrm{l}$, then the further 
water flooding is conducted until the water cut is $98 \%$, next the solution of Huading I or Haibo BI polymer surfactant is injected (whose concentration respectively is $800,1000,1500,2000 \mathrm{mg} / 1$ and the size of plug is one multiples of pore volume injected), finally, the further water flooding is conducted until the water cut is $98 \%$.

\section{B. Experiment Datas and Analysis}

The experiment result Huading I polymer surfactant is as shown as Table 1.

\begin{tabular}{|c|c|c|c|c|}
\hline \multicolumn{2}{|c|}{} & \multicolumn{2}{c|}{ Degree of reserve recovery (\%) } \\
\hline $\begin{array}{c}\text { The } \\
\text { concentration } \\
\text { of polymer } \\
\text { surfactant(mg } \\
\text { /) }\end{array}$ & $\begin{array}{c}\text { Wate } \\
\text { floodi } \\
\text { ng }\end{array}$ & $\begin{array}{c}\text { Polymer } \\
\text { flooding }\end{array}$ & $\begin{array}{c}\text { Polymer } \\
\text { surfactan } \\
\text { t flooding }\end{array}$ & $\begin{array}{c}\text { Overall } \\
\text { recovery } \\
\text { efficiency }\end{array}$ \\
\hline 800 & 42.87 & 17.93 & 12.51 & 73.31 \\
\hline 1000 & 44.89 & 16.89 & 15.78 & 77.56 \\
\hline 1500 & 43.97 & 16.75 & 19.68 & 80.40 \\
\hline 2000 & 44.76 & 16.03 & 21.11 & 81.90 \\
\hline
\end{tabular}

TABLE I. THE EXPERIMENT DATA OF CONCENTRATION OPTIMIZATION FOR HUADING I POLYMER SURFACTANT

It can be seen from Table 1 that the degree of reserve recovery of water flooding and polymer flooding is nearly, the further polymer surfactant flooding is comparative. Total volume of polymer surfactant increases with the increasing of concentration at the stage of polymer surfactant flooding, and the degree of reserve recovery at this stage increases, and the trend of increasing gets slowly. The recovery efficiency of Huading I polymer surfactant has increased by $3.27 \%$ when the concentration changes from $800 \mathrm{mg} / \mathrm{l}$ to $1000 \mathrm{mg} / \mathrm{l}$ and the degree of reserve recovery has increased by $3.9 \%$ when the concentration changes from $1000 \mathrm{mg} / 1$ to $1500 \mathrm{mg} / \mathrm{l}$, the degree of reserve recovery has only increased by $1.34 \%$ when the concentration changes from $1500 \mathrm{mg} / 1$ to $2000 \mathrm{mg} / \mathrm{l}$, which can show that the increasing of recovery efficiency gets slowly gradually with the gradually increasing of concentration. The concentration which is $1000 \mathrm{mg} / \mathrm{l}$ is an inflexion of the increasing of recovery efficiency, when the concentration is lower than $1000 \mathrm{mg} / \mathrm{l}$, the increasing of degree of reserve recovery increases gradually with the increasing of concentration, when the concentration is higher than $1000 \mathrm{mg} / \mathrm{l}$, the increasing of degree of reserve recovery decreases gradually with the increasing of concentration.
TABLE II. THE EXPERIMENT DATA OF CONCENTRATION OPTIMIZATION FOR HAIBO BI POLYMER SURFACTANT

\begin{tabular}{|c|c|c|c|c|c|}
\hline & \multicolumn{5}{|c|}{ Degree of reserve recovery (\%) } \\
\hline $\begin{array}{c}\text { Gr } \\
\text { ou } \\
\text { p }\end{array}$ & $\begin{array}{c}\text { The } \\
\text { concentrat } \\
\text { ion of } \\
\text { polymer } \\
\text { surfactant } \\
\text { (mg/l) }\end{array}$ & $\begin{array}{c}\text { Water } \\
\text { flooding }\end{array}$ & $\begin{array}{c}\text { Polym } \\
\text { er } \\
\text { floodi } \\
\text { ng }\end{array}$ & $\begin{array}{c}\text { Polyme } \\
\text { r } \\
\text { surfact } \\
\text { ant } \\
\text { floodin } \\
\text { g }\end{array}$ & $\begin{array}{c}\text { Overall } \\
\text { recovery } \\
\text { efficiency }\end{array}$ \\
\hline 1 & 800 & 40.98 & 15.61 & 12.92 & 69.51 \\
\hline 2 & 1000 & 42.71 & 14.38 & 14.58 & 71.67 \\
\hline 3 & 1500 & 43.73 & 14.49 & 16.14 & 74.36 \\
\hline 4 & 2000 & 43.77 & 16.39 & 17.42 & 77.58 \\
\hline
\end{tabular}

It can be seen from Table 2 that the degree of reserve recovery of water flooding and polymer flooding is nearly, the further polymer surfactant flooding is comparative. Total volume of polymer surfactant increases with the increasing of concentration at the stage of polymer surfactant flooding, and the degree of reserve recovery at this stage increases, and the trend of increasing gets slowly. The recovery efficiency of Haibo BI polymer surfactant has increased nearly by $1.66 \%$ when the concentration changes from $800 \mathrm{mg} / \mathrm{l}$ to $1000 \mathrm{mg} / \mathrm{l}$ and the degree of reserve recovery has increased by $1.5 \%$ when the concentration changes from $1000 \mathrm{mg} / \mathrm{l}$ to $1500 \mathrm{mg} / \mathrm{l}$, the degree of reserve recovery has only increased by $1.28 \%$ when the concentration changes from $1500 \mathrm{mg} / 1$ to $2000 \mathrm{mg} / \mathrm{l}$, which can also show that the increasing of recovery efficiency gets slowly gradually with the gradually increasing of concentration. The concentration which is $1000 \mathrm{mg} / \mathrm{l}$ is also an inflexion of the increasing of recovery efficiency, when the concentration is lower than $1000 \mathrm{mg} / \mathrm{l}$, the increasing of degree of reserve recovery increases gradually with the increasing of concentration, when the concentration is higher than $1000 \mathrm{mg} / 1$, the increasing of degree of reserve recovery decreases gradually with the increasing of concentration. The increasing of degree of reserve recovery can express the relationship between oil recovery and economic benefit, considering comprehensively the concentration which is dosage and the increasing of degree of reserve recovery which is economic benefit, optimal concentration injected of Haibo BI polymer surfactant is $1000 \mathrm{mg} / \mathrm{l}$.

Draw the map between the concentration and oil recovery, the increasing of oil recovery for polymer surfactant, as shown as Fig .1 and Fig .2. 


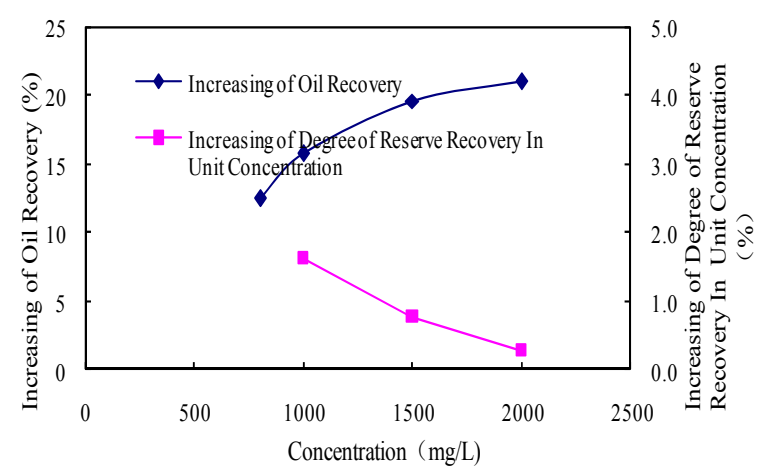

Figure 1. The relation graph between the concentration of Huading I polymer surfactant and the increasing of oil recovery $(1000 \mathrm{mg} / \mathrm{l})$

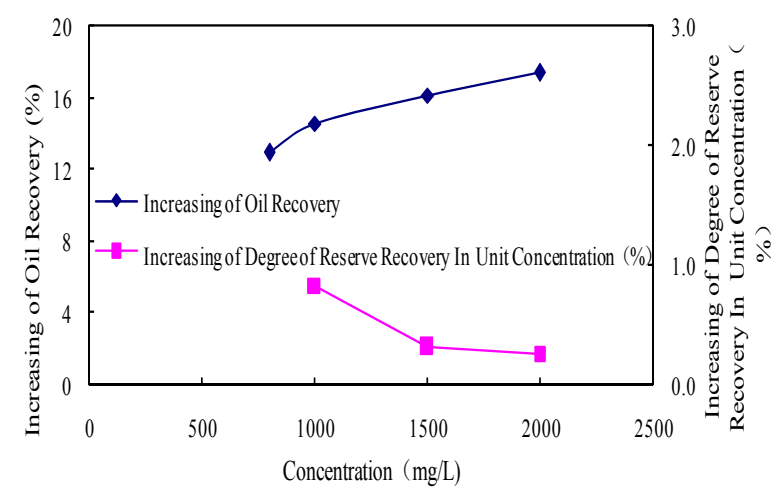

Figure 2. The relation graph between the concentration of Haibo BI polymer surfactant and the increasing of oil recovery $(1000 \mathrm{mg} / \mathrm{l})$

It can be seen from Fig .1 and Fig .2 that the increasing of degree of reserve recovery increases with the increasing of concentration for the two kinds of polymer surfactant, but the ranges of increasing are different, the increasing of degree of reserve recovery is the biggest when the concentration is $1000 \mathrm{mg} / \mathrm{l}$, and the increasing of degree of reserve recovery decreases when the concentration is higher than $1000 \mathrm{mg} / \mathrm{l}$. The increasing of degree of reserve recovery can express the relationship between oil recovery and economic benefit, optimal concentration injected of Huading I and Haibo BI polymer surfactant all is $1000 \mathrm{mg} / \mathrm{l}$.

\section{THE OPTIMIZATION OF OPTIMAL SLUGS FOR THE TWO KINDS OF POLYMER SURFACTANTS}

\section{A. Experiment Conditions and Schemes}

The experiment conditions in this part are the same as experiment of concentration optimization, this experiment has used the concentration optimized to conduct displacement experiment, compared the displacement efficiency when the slugs of polymer surfactant are different, ensured the relationship between slugs and oil recovery, and ensured optimal slugs to make preparations for further diplacement experiment. The experiment is water flooding to the water cut is $98 \%$, then polymer with medium molecular flooding whose concentration is $1000 \mathrm{mg} / \mathrm{l}$ and multiples of pore volume injected is 0.6 , next further water flooding, then slugs of Huading I and
Haibo BI polymer surfactant flooding with different multiples of pore volume injected, finally water flooding to the water cut is $98 \%$. The injection slugs for the two kinds of polymer surfactants respectively is $0.6,0.8,1.0$, 1.2 multiples of pore volume injected, and the above slugs are optimized.

\section{B. Experiment Results and Analysis}

The experiment results are as shown as Table 3 .

\begin{tabular}{|c|c|c|c|c|}
\hline \multirow{4}{*}{$\begin{array}{c}\text { Polymer } \\
\text { surfactant }\end{array}$} & $\begin{array}{c}\text { Degree of reserve recovery for the stages } \\
\text { flooding }\end{array}$ \\
\hline \multirow{7}{*}{ Huading I } & $\begin{array}{c}\text { Polymer } \\
\text { flooding }\end{array}$ & $\begin{array}{c}\text { Polymer } \\
\text { surfactant } \\
\text { flooding }\end{array}$ & $\begin{array}{c}\text { Overall oil } \\
\text { recovery }\end{array}$ \\
\cline { 2 - 5 } & 44.83 & 14.28 & 13.02 & 72.13 \\
\cline { 2 - 5 } & 42.16 & 15.90 & 19.68 & 77.74 \\
\cline { 2 - 5 } & 43.40 & 16.37 & 21.39 & 81.16 \\
\hline \multirow{4}{*}{ Haibo BI } & 45.20 & 15.02 & 13.17 & 73.39 \\
\cline { 2 - 5 } & 44.98 & 16.07 & 14.95 & 76.00 \\
\cline { 2 - 5 } & 45.22 & 14.90 & 19.22 & 79.34 \\
\cline { 2 - 5 } & 43.70 & 15.53 & 20.36 & 79.59 \\
\hline
\end{tabular}

\section{TABLE III. THE EXPERIMENT DATA FOR THE SLUG} OPTIMIZATION OF POLYMER SURFACTANT

It can be seen from Table 3 that the multiples of pore volume injected is bigger and the increasing of oil recovery during the polymer surfactant flooding stage is higher, but the increasing ranges of oil recovery are different. The degree of reserve recovery of Huading I polymer surfactant increases by $2.38 \%$ when the slugs increases from 0.6 multiples pore volume injected to 0.8 multiples pore volume injected, however, the degree of reserve recovery of Haibo BI polymer surfactant increases by $2.38 \%$; The degree of reserve recovery of Huading I polymer surfactant increases by $4.28 \%$ when the slugs increases from 0.8 multiples pore volume injected to 1.0 multiples pore volume injected, however, the degree of reserve recovery of Haibo BI polymer surfactant increases by $4.27 \%$; The degree of reserve recovery of Huading I polymer surfactant increases by $1.71 \%$ when the slugs increases from 1.0 multiples pore volume injected to 1.2 multiples pore volume injected, however, the degree of reserve recovery of Haibo BI polymer surfactant increases by $1.14 \%$. The above show that when the slug is 1.0 multiples pore volume injected, it is the turning point of increasing range for oil recovery; when the slug is lower than 1.0 multiples pore volume injected, the increasing range for oil recovery increases gradually, when the slug is higher than 1.0 multiples pore volume injected, the increasing range for oil recovery decreases gradually. This paper has used increased degree of reserve recovery in unit volume to optimize the best slug, and has compared the conditions of overall oil recovery and increased degree of reserve recovery in unit volume to optimize to polymer surfactant slug. 


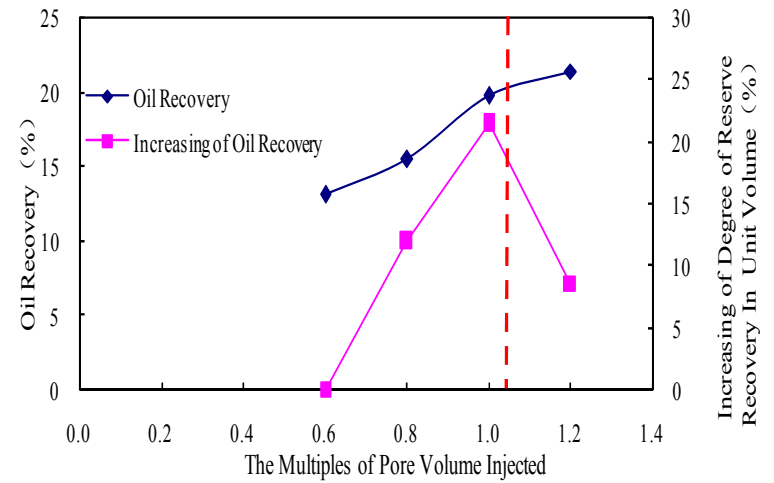

Figure 3. The curve between the concentration and oil recovery for the stage of Huading I polymer surfactant flooding

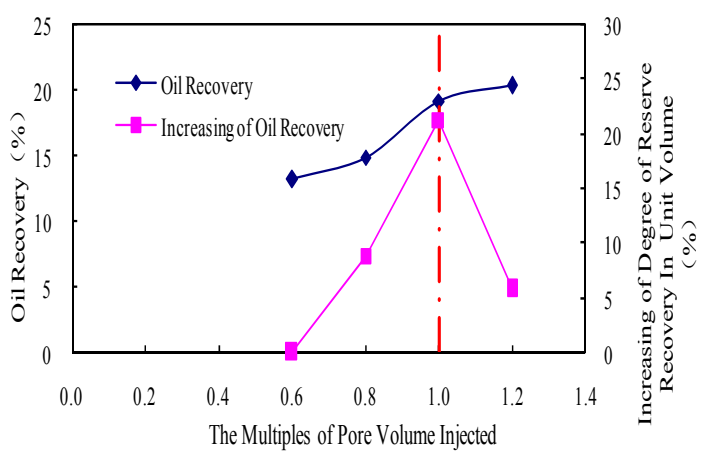

Figure 4. The curve between the concentration and oil recovery for the stage of Haibo BI polymer surfactant flooding

It can be seen from Fig .3 and Fig .4 that the increasing of oil recovery in the unit is the highest for the two polymer surfactants when the slug is 1.0 multiples of pore volume injected, which can show that the cost performance of the two polymer surfactants are the highest when the slug is 1.0 multiples of pore volume injected, so the optimization slugs for the two polymer surfactants are around 1.0 multiples of pore volume injected.

In the above contrast, it can be seen that optimized injection concentration for Huading I and Haibo BI polymer surfactants is $1000 \mathrm{mg} / \mathrm{l}$, and the slug is around 1.0 multiples of pore volume injected.

\section{CONCLUSIONS}

1. Displacement degrees of two kinds of polymer surfactant were compared when the concentration respectively is $800,1000,1500,2000 \mathrm{mg} / \mathrm{l}$. With gradually increasing concentration, the total recovery rate is on the increase, but its recovery rate increase growth rate is slow, the concentration of $1000 \mathrm{mg} / \mathrm{l}$ increased the amplitude recovery inflection point. Combined with the comprehensive economic considerations, two kinds of polymer surfactant concentration in the $1000 \mathrm{mg} / \mathrm{lwhen}$ the parity is highest, Huading I polymer surfactant and Haibo BI surfactant polymer the best injection concentration was $1000 \mathrm{mg} / \mathrm{l}$.

2. Comparing the displacement efficiency of two kinds of polymer surfactants under the condition of different slugs, it can be seen that the oil recovery of polymer surfactant increases with the increasing of injection slug, and the increasing of oil recovery gets to the biggest when the slug is 1.0 multiples of pore volume injected, which means that effective availability of polymer surfactant solution reduces when the slug is higher than .0 multiples of pore volume injected, and it shows that he cost performance of the two polymer surfactants are the highest when the slug is 1.0 multiples of pore volume injected, so the optimization slugs for the two polymer surfactants are around 1.0 multiples of pore volume injected.

\section{ACKNOWLEDGEMENTS}

This research was supported by jointly funded by the "Large oil and gas fields and coal-bed methane development"(2011ZX05016-002) of the national major projects and the open project "The research of seepage field and pressure field distribution of polymer surfactant flooding which after polymer flooding in major reservoir" of key laboratory of enhancing oil and gas recovery of ministry of education of northeast petroleum university.

\section{REFERENCES}

[1] R.D.Hester, L.M.Flesher, C.L.McCormick, "Polymer Solution Extension Viscosity Effects During Reservoir Flooding," SPE/DOE27823, 1994.

[2] Keliang Wang, Fenglan Wang, and Qun Li, "Study of Improving the Polymer Flooding Technology," Petroleum Industry Press, 1997, pp.8-10

[3] Fulin Zhao, "Oilfield Chemistry," China University of Petroleum Press.

[4] W B Gogarty, Mobility Control with Polymer Solutions. SPE. J, 1967, pp. 161-173.

[5] R. H. Christopher, S, "Middleman Power-Law Flow through a Packed Tube," I\&EC Fundamentals, vol. 4, 1965, pp. 422-427.

[6] R. Hass, F, "Durst Viscoelastec Flow of Dilute Polymer Solutions in Regularly Packed Beds," Rheologica Acta, 1982, pp. 566-571. 